\section{Addressing overuse in emergency medicine: evidence of a role for greater patient engagement}

\author{
Erika H. Newton \\ Department of Emergency Medicine, Stony Brook University, Stony Brook, NY, USA
}

Overuse of health care refers to tests, treatments, and even health care settings when used in circumstances where they are unlikely to help. Overuse is not only wasteful, it threatens patient safety by exposing patients to a greater chance of harm than benefit. It is a widespread problem and has proved resistant to change. Overuse of diagnostic testing is a particular problem in emergency medicine. Emergency physicians cite fear of missing a diagnosis, fear of law suits, and perceived patient expectations as key contributors. However, physicians' assumptions about what patients expect are often wrong, and overlook two of patients' most consistently voiced priorities: communication and empathy. Evidence indicates that patients who are more fully informed and engaged in their care often opt for less aggressive approaches. Shared decision making refers to (1) providing balanced information so that patients understand their options and the trade-offs involved, (2) encouraging them to voice their preferences and values, and (3) engaging them-to the extent appropriate or desired-in decision making. By adopting this approach to discretionary decision making, physicians are better positioned to address patients' concerns without the use of tests and treatments patients neither need nor value.

Keywords Medical overuse; Decision making; Patient participation

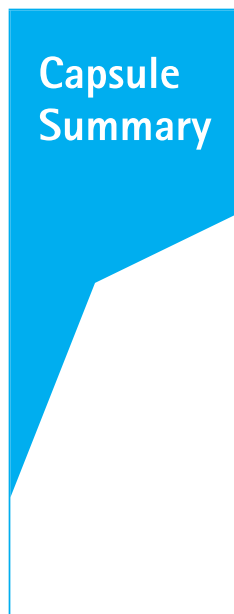

What is already known

Overuse of health care occurs on a wide scale and presents a threat to patient safety. Overuse of diagnostic testing in particular is a problem in emergency medicine. Fear of missing a diagnosis, fear of law suits, and perceived patient expectations are among the explanations most frequently cited by emergency physicians.

What is new in the current study

Shared decision making-informing and engaging patients, and eliciting their preferences for care-is an underutilized resource for tailoring medical care to the individual patient. Evidence indicates that patients who engage in it often opt for less aggressive approaches to care. Shared decision making has the potential to reduce the delivery of care that may be neither beneficial to, nor desired by, patients.
eISSN: 2383-4625

Received: 1 May 2017

Revised: 5 June 2017

Accepted: 30 June 2017

Correspondence to: Erika H. Newton Department of Emergency Medicine, Stony Brook University Medical Center, Health Sciences Center Level 4 Room 80, Stony Brook, NY 11790-8350, USA E-mail: erika.newton@ stonybrookmedicine.edu

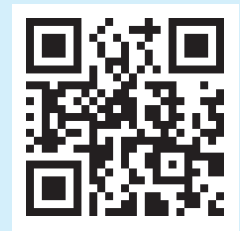

How to cite this article: Newton EH. Addressing overuse in emergency medicine: evidence of a role for greater patient engagement. Clin Exp Emerg Med 2017;4(4):189-200.

This is an Open Access article distributed under the terms of the Creative Commons Attribution Non-Commercial License (http:// creativecommons.org/licenses/by-nc/4.0/). 


\section{INTRODUCTION}

A significant portion of the medical care patients receive is of little or no benefit, or is as likely to harm as help. According to a 2012 Institute of Medicine report, unnecessary services, commonly referred to as overuse, comprise the single largest source of waste in US health care-waste accounting for as much as 30 percent of all health care spending. 'The implications of overuse for patient safety are equally troubling. Tests, treatments, and even intensive health care settings, used in circumstances where they are unlikely to help, expose patients to unnecessary risk. This may involve direct harms, such as a Clostridium difficile infection resulting from antibiotics prescribed for a viral infection; or indirect harms, as when a computed tomography (CT) scan performed for low-risk headache leads to false positive or clinically unimportant findings, generating anxiety for the patient and the inconvenience and risk of further testing or treatment.

Addressing overuse has been identified as a national priority for US health care reform. ${ }^{2}$ Recent years have seen widespread calls for change, ${ }^{3,4}$ high-profile efforts to raise physician awareness such as the Choosing Wisely initiative, ${ }^{5}$ dedicated series in leading medical journals (JAMA Internal Medicine's "Less is more," the BMJ's "Too much medicine," the Lancet's "Right care"), and a rapidly expanding research literature on the topic. ${ }^{6}$ Yet in practice, progress has been slow, ${ }_{1}^{7,8}$ even as physicians themselves acknowledge the problem. ${ }^{9,10}$ This review will examine overuse in the context of emergency medicine (EM), and emerging evidence of an underutilized mechanism for reducing it.

\section{EXAMPLES OF OVERUSE IN EM}

Overuse takes different forms in different specialties. Unnecessary invasive procedures predominate in some; medications and screening tests in others. In EM, overuse of diagnostic testing is the problem. ${ }^{11}$ In a 2015 survey, over 85\% of 435 emergency physicians (EPs) felt that too many diagnostic imaging tests were being ordered in their own departments, and 97\% felt that at least some (mean 22\%) of the advanced imaging studies they themselves ordered were not medically justified. ${ }^{9}$ In 2014, the American College of Emergency Physicians, a latecomer to Choosing Wisely, produced a list of 10 recognized sources of overuse in EM to avoid (Table 1); advanced imaging, mainly CT, accounts for half of these.

Much of the evidence of CT overuse comes from observations that, despite steep increases in CT use for a variety of indications such as trauma-related conditions, pulmonary embolus, and respiratory infections, no corresponding improvement in clinically important disease detection has been seen. ${ }^{12-14}$ Other studies have shown high rates of guideline-discordant CT use, including a third of CTs ordered for minor head injury ${ }^{13}$ and a similar proportion of those used to rule out pulmonary embolus. ${ }^{14}$ Of note, CT ordering rates vary strikingly across EPs-as much as 8-fold, for example, in the case of abdominal CT for patients not requiring admission. ${ }^{15}$

Additional examples of overtesting and its consequences in EM include the routine initiation of, or referral for, cardiac work-ups for low or very low-risk chest pain patients, which increase cardiac catheterization and revascularization rates without improving outcomes ${ }^{16}$; the use of D-dimer in patients at very low risk of pulmonary embolus, leading to excess imaging ${ }^{17}$; and the ordering of

Table 1. Common forms of overuse in emergency medicine as identified by American College of Emergency Physicians for the Choosing Wisely initiative

Computed tomography (CT) scans of the head in emergency department patients with minor head injury who are at low risk based on validated decision rules.

Placing indwelling urinary catheters in the emergency department for either urine output monitoring in stable patients who can void, or for patient or staff convenience.

Failure to engage available palliative and hospice care services in the emergency department for patients likely to benefit.

Antibiotics and wound cultures in emergency department patients with uncomplicated skin and soft tissure abscesses after successful incision and drainage and with adequate medical follow-up.

Instituting intravenous fluids before doing a trial of oral rehydration therapy in uncomplicated emergency department cases of mild to moderate dehydration in children.

CT of the head in asymptomatic adult patients in the emergency department with syncope, insignificant trauma and a normal neurological evaluation.

CT pulmonary angiography in emergency department patients with a low-prestest probability of pulmonary embolism and either a negative Pulmonary Embolism Rule-Out Criteria or a negative D-dimer.

Lumbar spine imaging in the emergency department for adults with non-traumatic back pain unless the patient has severe or progressive neurologic deficits or is suspected of having a serious underlying condition (such as vertebral infection, cauda equina syndrome, or cancer with bony metastasis).

Prescribing antibiotics in the emergency department for uncomplicated sinusitis.

Ordering $\mathrm{CT}$ of the abdomen and pelvis in young otherwise healthy emergency department patinets (age $<50$ ) with known histories of kidney stones, or ureterolithiasis, presenting with symptoms consistent with uncomplicated renal colic. 
urinalysis for asymptomatic patients, risking inappropriate antibiotic treatment. ${ }^{18}$ Common instances of primary overtreatment in EM include prescribing antibiotics for acute bronchitis, ${ }^{19}$ and placing medically unnecessary urinary catheters. ${ }^{20}$

\section{INSIGHTS INTO OVERUSE FROM STUDIES OF PRACTICE VARIATION}

Research dating back to the 1970s lent valuable insights into overuse. Epidemiologist and physician John Wennberg and a colleague, tracking health care delivery patterns in Vermont and Maine, made what was at the time a surprising discovery: rates of surgical procedures varied markedly from one part of a state to anothereven between neighboring districts. ${ }^{21}$ Finding no patient factors to explain, for example, nearly four-fold differences in tonsillectomy rates among school children, they determined that "variations tend to reflect differences in the way particular individuals and groups practice medicine."

Subsequent work by Wennberg and the Dartmouth Atlas Project showed that greater health care utilization in a given region mirrors greater concentrations of local health care resources, e.g., specialists, medical technologies and hospital beds-but is associated neither with sicker patients to begin with nor with better outcomes. ${ }^{22,23}$ Supply-sensitive care, as such care is known, is encouraged by the combined effects of a fee-for-senvice, third-party payment model. But the wider insight is that substantial variations in care may be driven by factors having nothing to do with patients themselves, nor with scientific evidence, and to this extent are inconsistent with the aims of health care. An understanding of this concept is central to the study of overuse.

\section{DRIVERS OF OVERUSE IN EM}

Financial incentives, while undoubtedly behind much of the overuse in health care, are only one among many non-clinical pressures acting on physician decision making. In fact, personal financial motive is unlikely to explain most overuse in EM, given that many EPs-particularly those in the academic sector or paid on salary-are entitled at best only to indirect remuneration for individual services provided. A bigger factor, EPs say, is fear. In a 2015 survey by Kanzaria et al., ${ }^{9}$ EPs identified fear of missing a low-probability diagnosis (69\%) and fear of litigation (64\%) as the leading contributors to unnecessary imaging in EM. Indeed, defensive medicine and more specifically "assurance behaviors"-ordering tests or treatments with the aim of protecting the physician against future legal action by the patient or patient's family-are widespread among EPs. ${ }^{11}$
Risk-aversion and intolerance for uncertainty are unsurprising, given the context in which EPs function. EM pairs high-stakes decision making with a unique set of challenges. These include lack of time (limiting the opportunity to gather a thorough history, learn potentially relevant psychosocial or other contextual factors, and establish trust), lack of an ongoing relationship between physician and patient, inconsistent access to prior medical records, and uncertain access by patients to appropriate follow-up. There is also a widespread perception among EPs that they face especially high medicolegal risk, but a 2011 Research and Development (RAND) Corporation study indicated only slightly aboveaverage claims rates, average payout rates, and below-average (both mean and median) total payouts."

Additional drivers of overuse cited by EPs in the survey by Kanzaria et al. ${ }^{9}$ were perceived patient or family expectations (38\%), perceived local $(39 \%)$ or EM-wide (35\%) standard of care, and lack of time (24\%); administrative pressure and personal reimbursement were infrequently cited. Other likely contributors include the ease and speed with which tests can be obtained, especially with the advent of electronic order entry ${ }^{24}$; the inconsistent availability of high-quality evidence synopses; and quality metrics which track underuse but less commonly overuse. ${ }^{25}$ Importantly, these myriad influences are offset by no comparable influences in the opposite direction (toward judicious, evidence-based care) and have therefore been called a "perfect storm" of conditions for overuse. $^{26}$

\section{REDUCING OVERUSE}

Is change possible under such circumstances? Large-scale reform of health care overuse, most believe, will require systems-level solutions, including alternative payment models that reward quality over volume; national initiatives aimed at promoting evidencebased standards and appropriate-use criteria; administrative-level efforts such as feedback to physicians on test-ordering metrics; and medical education reform. Surveyed EPs say they believe tort reform is needed above all, but studies to date have failed to show a reduction in practice intensity (e.g., imaging rates) in states which have undergone tort reform. ${ }^{27}$ Measures to curb overuse will, in any case, take time. Meanwhile, from the standpoint of the practicing EP, it has been argued, a risk analysis will continue to favor doing more rather than less. ${ }^{28}$

One influence on physicians' decisions, however, though currently perceived as part of the problem, may have the potential instead to help: patients' own preferences for care. Physicians are not only duty-bound to place patients' interests first in making health care decisions, patients have a legal right to information 
about their health care options, and to weigh in on these - to refuse specific care, for example, or to request one approach over another, where more than one reasonable option exists. Engaging patients in their health care is increasingly seen, too, as an ethical mandate for physicians. ${ }^{29}$ In addition, this may be the only means of ensuring that services provided are valued by the patient. Health care that informed patients don't value, insofar as it is preferencesensitive (may be approached in more than one way) amounts to overuse. A growing body of research, detailed below, suggests that a simple physician-led change (greater information exchange and engagement with patients) has the potential to reduce such care.

\section{UNTAPPED PATIENT PERSPECTIVE}

\section{Patient expectations as perceived by physicians}

Both elsewhere in medicine and in EM, physicians are frequently swayed by what they perceive their patients' (or patients' families') expectations to be. ${ }^{9,30}$ Mangione-Smith et al. ${ }^{31}$ found physician perception of parent expectations to be the sole predictor of whether antibiotics were prescribed ( $62 \%$ vs. $7 \%$ of the time) for children with upper respiratory infections. A national survey of 1,662 physicians across a range of specialties found that 36\% would order an unnecessary magnetic resonance imaging (MRI) for acute low back pain if the patient insisted. ${ }^{32}$

But physicians are often mistaken about patient expectations and preferences, even as they try to meet them. EPs treating patients with diarrhea have been found more likely to prescribe antibiotics if they believe patients expect them, but they correctly identify expectations only a third of the time. ${ }^{33}$ And in MangioneSmith et al.'s study, ${ }_{1}{ }^{1}$ antibiotic prescriptions reflected parents' perceived expectations, but not their actual expectations. Much evidence has shown that physicians' assumptions regarding patient priorities are frequently incorrect ${ }^{34,35}$ and, furthermore, that their decisions on behalf of patients differ from those they would make for themselves. ${ }^{36}$

Even when physicians are correct about patients' expectations, they may assign them too much weight: fulfillment of expectations has not been shown to be a consistent or dominant factor in patient satisfaction. A review of 19 studies of visit-specific expectations found only a modest relationship between expectations and satisfaction. ${ }^{37}$ A subsequent study of over 3,000 adults with acute cough found that while satisfaction was somewhat associated with whether hoped-for antibiotics were prescribed (odds ratio 0.39 ), 93\% of patients were satisfied even though only half had received antibiotics. ${ }^{38}$ Other studies report similar findings, ${ }^{33,39}$ or no association at all between patient satisfaction and whether pre-visit expectations were met. ${ }^{31,40}$ Importantly, while the evidence links medically unnecessary care less to patients' demands than to physicians' perceptions of these, such care has been found reinforce patient expectations in subsequent medical encounters. ${ }^{41-43}$

To the extent that meeting patients' expectations for specific tests or treatments sometimes does predict greater satisfaction, patient satisfaction can be at odds with health outcomes. In a randomized controlled trial of imaging versus no imaging for patients with low back pain, for example, patients in the imaging group were more likely to report pain at 3 months and to have consulted their physician again, yet were ultimately more often satisfied with their care. ${ }^{44}$ In similar study comparing X-rays and MRI, back pain patients who got MRI were more satisfied despite comparable pain and disability scores and a trend toward more operations. ${ }^{45}$

\section{Patient expectations as reported by patients}

The pursuit of patient satisfaction is no guarantee of high-quality care-nor even, where patients' preferences are inferred and not confirmed, of satisfaction itself. But there is nevertheless much to be learned from what patients say matters to them.

Studies have overwhelmingly found the quality of physicianpatient communication to be a top patient priority. ${ }^{19,31,40,46}$ Patients rank the provision of information as highly $\mathrm{as}^{47}$ or higher than $^{31}$ that of specific services. Provider interpersonal behavior or humanism, likewise, has been found to be a strong predictor of satisfaction among ED patients, ${ }^{48}$ empathic caring ranking higher even for patients than information in one ED study.9 How much time patients feel the physician spent listening to them can also predict satisfaction levels. ${ }^{40}$

Failure of physicians to deliver on these expectations is not only a common patient complaint, it is among the factors most frequently cited by patients who sue. ${ }^{50} \mathrm{~A}$ systematic review of 14 studies found that 26\% to 95\% (median 52\%) of patients were dissatisfied with the information they received and desired more. ${ }^{51}$ In interviews with families who filed malpractice claims following perinatal injuries, most complained about at least one aspect of physician-patient communication, including "would not answer questions," "would not listen," or "attempted to mislead" them; by way of comparison, only $25 \%$ cited money as a factor..$^{52}$ Even among patients who had not sued their physicians, those whose obstetricians had frequent malpractice claims were twice as likely to complain about their care as those whose obstetricians had never been sued, and the most frequent source of complaints was physician-patient communication: feeling rushed, not being offered information, not being listened to, and perceiving a lack of concern or respect on the physician's part. ${ }^{53}$ 


\section{Patient concerns}

Patients often have specific concerns which they may or may not volunteer. Failure of physicians to identify and address these, coupled with the reflexive ordering of tests or treatments, can represent a missed opportunity to reassure through dialogue and education. For example, physicians may assume parents expect antibiotics when instead they may merely be looking for assurances that their child's illness isn't serious, or validation of their decision to seek medical care. ${ }^{54}$ And for a majority of adults with upper respiratory symptoms, the goal is a diagnosis, ${ }^{5,56}$ not necessarily antibiotics. ${ }^{43,55}$

Requests for imaging, e.g., among patients with low back pain, may reflect a desire by patients for validation of their suffering. ${ }^{57}$ Demands driven in this way by emotional, not rational, motives may be possible to address at an interpersonal level. A study of patients with low back pain found that functional limitation and the desire to know the cause were patients' main concerns. ${ }^{58}$ And an ED study by Melnick et al. ${ }^{49}$ on imaging decisions in minor head trauma found that reassurance, listening, and having their concerns addressed were the most frequently occurring themes for patients.

Additional factors that may contribute to patient requests for unnecessary care include lack of knowledge, direct-to-consumer advertising, moral hazard resulting from third-party payment, and the fear that physicians and health care facilities may ration care to cut costs. Rather than undermine the value of communication and empathy, however, these challenges underscore the importance of addressing patients' expectations explicitly and forthrightly, providing relevant education, listening, and reassuring. Indeed, evidence exists that brief patient education can increase patient satisfaction when, for example, imaging is not recommended. ${ }^{41}$ By comparison, diagnostic tests for symptoms with low risk of serious illness have not been consistently found to reassure patients, decrease anxiety, or resolve symptoms. ${ }^{59}$

\section{Patient attitudes toward health interventions}

Patients frequently hold beliefs about health care that run counter to the evidence. ${ }^{60,61}$ In particular, patients tend to believe that more care means higher-quality, better care, ${ }_{1}^{62}$ and to be biased in favor of intervention. ${ }^{63}$ Most overestimate the benefits of health care and underestimate the harms, a large systematic review has shown. ${ }^{64}$

But patients' beliefs about health care are at least in part a reflection of their prior experiences with it. Intervention bias on the part of physicians is well documented ${ }^{63,65}$; like patients, physicians tend to assume benefits and overlook the possibility of harm. ${ }^{65} \mathrm{In}$ a large national survey examining decision making processes, most patients having faced a discretionary screening test decision reported being advised by their physicians to opt for the test and infrequently informed of reasons not to. ${ }^{66}$ In audio recordings of cardiologists discussing treatment of stable coronary artery disease, stents were recommended in most cases, but harms, benefits and treatment alternatives were rarely fully discussed. ${ }^{67}$

Evidence suggests, however, that when patients are provided with balanced information, they show less inclination to undergo interventions. In considering whether to take medication for cardiovascular disease prevention, for example, older patients have been found to be more sensitive to knowledge of adverse medication effects than to knowledge of benefits. ${ }^{68}$ And patients with stable coronary artery disease are less likely to agree to an invasive procedure, the more elements of informed decision making are fulfilled. ${ }^{67}$

\section{SHARED DECISION MAKING}

Taken together, the evidence reviewed above argues for medical decision making that is centered on information exchange and explicitly identifies and addresses the individual patient's concerns and preferences. This two-way exchange between patient and physician is the essence of shared decision making (SDM).

SDM arose as a concept in the 1980s, propelled by a cultural shift in medicine toward greater patient autonomy and away from paternalism. It is by now widely endorsed. In its 2001 report, "Crossing the quality chasm: a new health system for the 21st century," the Institute of Medicine explicitly encourages SDM, recommending that patients "be given the necessary information and the opportunity to exercise the degree of control they choose over health care decisions that affect them." ${ }^{69}$ American College of Emergency Physicians's code of ethics contains similar language. ${ }^{70}$ The Affordable Health Care Act also contains a provision aimed at promoting SDM.

The following definition of SDM emerged from the 2016 Academic Emergency Medicine Consensus Conference on the topic: "A conversation between...clinician and...patient in which they figure out together what to do to address the patient's situation."71 SDM has been described as a continuum: how and to what extent a patient participates in decision making may vary according to the patient's desire and ability, and to how value-laden vs. value-neutral a decision may be. ${ }^{72}$ As an answer to the issues outlined earlier-misunderstood patient priorities, patient dissatisfaction with physician communication efforts, and intervention bias often stemming from lack of information-SDM is less about patients making decisions than about enabling them to do so, through information exchange; inviting them to, to the extent they desire; 
and, wherever possible, arriving at decisions which reflect their values and preferences.

SDM is no less applicable to EM than to other specialties, in all but the most immediately life-threatening situations, ${ }^{73}$ assuming (1) an awake patient able to absorb information about the medical problem and the options for approaching it, and (2) more than one reasonable option. A high level of understanding is not required, but information should be commensurate with the patient's ability to use it and readiness to receive it. As a rule of thumb, not engaging patients in their care assumes: (1) a single best approach exists, (2) the physician knows the best approach and consistently applies it, (3) the physician is in a better position than the patient to evaluate trade-offs between approaches, and (4) the physician has a legitimate investment in the decision, i.e., has the patient's interests in mind. ${ }^{74}$

\section{Evidence of benefit}

Evidence of the benefits of SDM comes mostly from studies using decision aids (DAs)-visually accessible information displays in a variety of formats aimed at facilitating SDM. A large Cochrane review found that, compared with those getting usual care, patients who use DAs demonstrate greater knowledge, more accurate perception of treatment benefits and harms, and less tendency to remain passive during decision making, and they experience no greater anxiety. ${ }^{75}$ Benefits from SDM have also been seen in the absence of DAs. For example, an observational study of older ED patients with acute musculoskeletal pain found that patients who reported greater participation in decision making were more satisfied with the discharge pain medications. ${ }^{76}$

Importantly, informed patients encouraged to consider their preferences appear to choose more conservative options. Patients with back pain who watched a video of other patients explaining their treatment preferences were less likely to choose surgery than patients receiving only written information; 1-year outcomes were the same. ${ }^{77}$ And in the Cochrane review, patients using DAs chose more conservative options than their physicians. ${ }^{75}$

Studies of DAs in the EM literature support this finding. In one, ED patients with chest pain or dyspnea were presented with a hypothetical scenario involving a standardized description of the workup for possible pulmonary embolus, along with a DA describing the risks of CT in low-probability patients and of deferring imaging assuming a D-dimer less than twice the upper limit of normal; over a third of patients elected to defer imaging. ${ }^{78}$ Two other studies involved low-risk chest pain patients. In one, the Chest Pain Choice DA, an individualized pictogram indicating risk of an adverse event, was found to safely reduce rates of admission for observation. ${ }^{79}$ In the other, patients given a printout of their pretest probability were less likely to opt for CT, more satisfied with physician explanations, and less likely to return to the ED within 7 days, with no increase in missed or delayed diagnosis. $^{80}$

SDM is far from a guarantee of less extensive testing. In fact, concerns have been raised that linking it to the hope of greater efficiency could detract from its intended focus on patients' interests. ${ }^{81,82}$ Few if any have suggested that SDM be employed in the interest of saving money. But addressing unnecessary care is very much in patients' interests. SDM is the most direct way to ensure that patients aren't subjected to preference-sensitive interventions they don't value or, worse, are no more likely to help than to harm them.

\section{How patients feel about SDM}

Most patients favor at least some level of involvement in health care decisions. An overwhelming majority wish to be offered choices and to be asked their opinion; interest in helping make the final decision varies somewhat but is nevertheless substantial. ${ }^{83}$ In a European study, 70\% of 8,000 patients had a high desire for SDM. ${ }^{84}$ More than $90 \%$ in one US study wanted a shared role in deciding on screening and diagnostic tests. ${ }^{85}$ In an ED study, parents of children with lacerations overwhelmingly wished to be included in medical decisions affecting their children. ${ }^{86}$ Moreover, $71 \%$ of studies in or after 2000 found that most patients wanted role in decision making, compared with only $50 \%$ of studies from before $2000 .^{87}$

The reasons for variable patient interest in SDM are worth considering. For example, some patients cite authoritarian physician style and a fear of being labeled difficult as factors, ${ }^{88}$ and others may feel they lack requisite information or skills specific to the encounter. ${ }^{89}$ White race, more education, ${ }^{90}$ and younger age ${ }^{83}$ have been found to predict greater patient participation in medical encounters. It is possible to conclude that patient reluctance to participate is in part a dynamic phenomenon, some of whose sources may be expected to diminish with time.

\section{How EPs feel about SDM}

In a 2016 survey, SDM was endorsed by a majority of 709 EPs across a range of decision categories, including invasive procedures, diagnostic testing (particularly CT scans), medications, and disposition. ${ }^{91}$ At least half of respondents considered it appropriate for use "all or most of the time" in a variety of clinical scenarios (antibiotics for severe sepsis was the sole exception), particularly decisions that are either higher risk or associated with controversy or uncertainty. Similarly, EPs surveyed in 2015 considered SDM to be widely applicable, with over half of cases they see in- 
volving a choice among reasonable management options. ${ }^{92}$ An overwhelming majority of EPs felt SDM could help reduce unnecessary care. $^{9}$

Still, EPs estimated that they use SDM only 58\% of the times it would be appropriate. ${ }^{92}$ Unsurprisingly, EPs reporting less use of SDM in their practice were more likely to cite obstacles. Most obstacles were patient-related and, notably, ran counter to the evidence. For example, the most frequent concern was that patients would prefer to leave decisions in physicians' hands. About half of EPs also worried that, given a choice, patients would tend to opt for more aggressive care than they need, would find SDM too complicated, and wouldn't know how to choose among options. ${ }^{92}$ As discussed previously, the evidence does not substantiate these concerns. Most EPs were not concerned that SDM would increase length of stay. ${ }^{92}$

\section{Challenges for SDM}

SDM faces several challenges. Vulnerable populations are one: patients lacking health literacy and in other ways disadvantaged have been found less willing to participate in medical decisions. ${ }^{51}$ They ask fewer questions on average, receive less information, and are less satisfied with their encounters with physicians. ${ }^{93}$ Nevertheless, evidence suggests they can derive at least as much benefit from SDM as other patients, perhaps more. ${ }^{94}$ To be equitable, SDM should be made accessible to all subpopulations able to benefit from it. Determining optimal approaches for patients of wide-ranging knowledge and abilities, however, adds complexity to the task.

A second potential hurdle is that SDM is widely believed to require physician education and training, ${ }^{95,96}$ if only to encourage its use. Uptake to date has indeed been modest, ${ }^{92}$ and untrained physicians engage patients to a lesser degree than they believe themselves to. ${ }^{97}$ Training can impart more uniform skills and standards, and familiarize physicians with the use of DAs. However, effective patient engagement starts with skills largely already available to (even essential for) physicians: listening, explaining, and expressing compassion.

Table 2. Decision aids: on-line resources

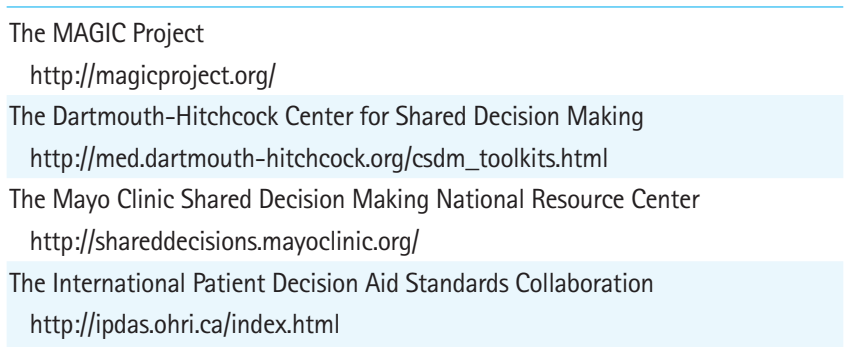

Probably the greatest difficulties for SDM, however, are the limitations of physicians' information base and its application to the individual patient-obstacles to effective and evidence-based practice regardless of the level of patient engagement. Physicians have been found to lack salient and up-to-date knowledge, ${ }_{1}^{98,99}$ and may settle for unsupported theory based on physiologic explanations. $^{63}$ They are prone to biases ${ }^{63,100}$ and uncomfortable with uncertainty. ${ }^{101}$ The sheer volume of published research findings leaves physicians largely dependent on secondary information sources; these vary in quality and coverage.

Research findings can offer false hope of benefits in several ways. Reversal of standard-of-care practices is common, ${ }^{102}$ in part because science is necessarily a dynamic endeavor, but also because of flawed methodologies and because of publication bias favoring positive studies ${ }^{103}$-commercial interests lend sizeable financial incentives for these. Harms have been shown to be much less routinely evaluated and reported than benefits, in the research literature. ${ }^{104}$ And studies often fail to indicate how the relative benefits and harms of an intervention may differ across patients, and to provide evidence in the form of pretest probabilities allowing a Bayesian approach to decision making. ${ }^{105}$

Clinical guidelines should in theory provide objective, up-todate evidence summaries to aid decision making, but two problems currently limit their utility. First, many lack impartiality, due to a heavy presence of financial and other conflicts of interest among guideline authors and panel chairs. ${ }^{106}$ Second, in aiming to reduce practice variation, guidelines typically default to strong recommendations which de-emphasize patient preference. ${ }^{107,108}$ Uniformity of practice is an unreasonable goal when no single approach to management is clearly superior.

Guidelines should offer flexible approaches and encourage patient engagement, describing potential harms as well as benefits for each approach. Otherwise, they pit individual choice against recommendations that may be held up as a standard of practice, creating tension for physicians and patients alike. DAs were created to address this need. They are becoming available online in increasing numbers (Table 2).

Table 3. Questions to guide shared decision making

What will happen if we wait and watch?

What are your test or treatment options?

What are the benefits and harms of these options?

How do the benefits and harms weigh up for you?

Do you have enough information to make a choice?

Reproduced from Hoffmann TC, et al. Med J Aust 2014;201:35-9, with permission from the Medical Journal of Australia. ${ }^{95}$ 
Table 4. A 6-step approach to fielding patient requests for low-value diagnostic tests

Understand the patient's concerns and expectations before addressing them Validate the patient's concerns and emotions using empathy and normalization. Inform the patient about reassuring features of the history and examination. Explain that you do not recommend the test because risks outweigh benefits. Flexibly negotiate alternatives to testing.

Explore for residual concerns.

Reproduced from Fenton JJ, et al. JAMA Intern Med 2016;176:191-7, with permission from the American Medical Association. ${ }^{110}$

\section{A practical guide to SDM}

Hoffmann et al. ${ }^{95}$ have proposed five questions to guide SDM (Table 3). Note that DAs, where available, can be a helpful adjunct but cannot currently be considered essential; SDM with and without DAs has yet to be formally compared.

Information provided to patients should be presented at a level of detail commensurate with patients' interest and intellectual ability, and, where knowable, with the potential significance to the patient of the choice to be made. Caverly et al. ${ }^{109}$ argue that when patients find information too technical or detailed they may miss the bottom line. They offer these simple talking points for patients weighing the decision to have a CT scan: (1) "the lifetime risk of developing cancer from exposure to radiation from CT scans appears to be real," (2) "we as clinicians take this risk seriously enough to consider other options for testing that do not use radiation, including physical exam and/or watchful waiting," and (3) "the small magnitude of the risk is vastly outweighed by the benefits of appropriate imaging."

What if the patient wants care that will not help? Fenton et al. ${ }^{110}$ suggests a 6-step approach (Table 4). Mangione-Smith et al. ${ }^{111}$ found that offering parents a contingency plan when children with respiratory symptoms were not given an antibiotic was associated with higher mean satisfaction scores. Importantly, SDM does not obligate physicians to provide the care patients ask for. SDM respects patient autonomy, but autonomy is not the only consideration ${ }^{112}$; refraining from giving non-beneficial care is part of non-maleficence, or doing no harm, and explaining a decision not to provide care has value as patient education. ${ }^{113}$

What if instead the patient declines care that the physician feels is important? For example, when the risk of serious disease is low but the stakes are high? Situations will inevitably arise in which a patient's decision creates discomfort for the physician. With or without SDM, patient autonomy amounts to the freedom to refuse care, assuming a patient has decisional capacity and is sufficiently informed. A systematic review on the question of whether SDM influences medical malpractice litigation found insufficient empirical data to draw conclusions, but some evidence sug- gested that disregard of patient preferences and failure to provide information increased risk. ${ }^{114}$ Interestingly, most EPs already assume that using and documenting SDM lowers medicolegal risk. ${ }^{91}$

When a physician is uncomfortable with a patient's decision, additional safeguards should be utilized where possible, such as ED observation or early follow-up, and the discussion should be documented. SDM should in general be documented, though there is as yet no standard approach for doing so.

\section{CONCLUSION}

Many nonpatient factors influence medical decision making. Overwhelmingly, these tend in the direction of encouraging more health care. The result is often medically unnecessary care, or overuse, which not only adds needless cost but exposes patients to avoidable risks. Physician assumptions about patient preferences also affect medical decisions and contribute to unnecessary care. These assumptions are wrong surprisingly often, and even when correct overlook two of patients' most consistent priorities: communication and empathy by their physicians. By providing balanced information so patients understand their options and any tradeoffs involved, encouraging them to voice their preferences and values, and engaging them (to the extent appropriate or desired) in decision making, physicians are in a better position to address patients' concerns without the use of tests and treatments patients neither need nor value.

\section{CONFLICT OF INTEREST}

No potential conflict of interest relevant to this article was reported.

\section{REFERENCES}

1. Smith MD; Institute of Medicine. Best care at lower cost: the path to continuously learning health care in America. Washington, DC: National Academy Press; 2012.

2. National Quality Forum. National priorities and goals: aligning our efforts to transform America's healthcare [Internet]. Washington, DC: National Quality Forum; 2008 [cited 2017 Apr 6]. Available from: http://www.qualityforum.org/Setting _ Priorities/NPP/Input_into_the_National_Quality_Strategy. aspx.

3. Berwick DM, Hackbarth AD. Eliminating waste in US health care. JAMA 2012;307:1513-6.

4. Carpenter CR, Raja AS, Brown MD. Overtesting and the downstream consequences of overtreatment: implications of "pre- 
venting overdiagnosis" for emergency medicine. Acad Emerg Med 2015;22:1484-92.

5. Choosing Wisely. An initiative of the ABI Foundation [Internet]. Philadelphia, PA: American Board of Internal Medicine Foundation; 2017 [cited 2017 Apr 6]. Available from: http:// www.choosingwisely.org/.

6. Morgan DJ, Dhruva SS, Wright SM, Korenstein D. 2016 Update on medical overuse: a systematic review. JAMA Intern Med 2016;176:1687-92.

7. Kale MS, Bishop TF, Federman AD, Keyhani S. Trends in the overuse of ambulatory health care services in the United States. JAMA Intern Med 2013;173:142-8.

8. Rosenberg A, Agiro A, Gottlieb M, et al. Early trends among seven recommendations from the Choosing Wisely campaign. JAMA Intern Med 2015;175:1913-20.

9. Kanzaria HK, Hoffman JR, Probst MA, Caloyeras JP, Berry SH, Brook RH. Emergency physician perceptions of medically unnecessary advanced diagnostic imaging. Acad Emerg Med 2015;22:390-8.

10. Sirovich BE, Woloshin S, Schwartz LM. Too little? Too much? Primary care physicians' views on US health care: a brief report. Arch Intern Med 2011;171:1582-5.

11. Studdert DM, Mello MM, Sage WM, et al. Defensive medicine among high-risk specialist physicians in a volatile malpractice environment. JAMA 2005;293:2609-17.

12. Drescher FS, Sirovich BE. Use of computed tomography in emergency departments in the United States: a decade of coughs and colds. JAMA Intern Med 2016;176:273-5.

13. Melnick ER, Szlezak CM, Bentley SK, Dziura JD, Kotlyar S, Post LA. CT overuse for mild traumatic brain injury. Jt Comm J Qual Patient Saf 2012;38:483-9.

14. Venkatesh AK, Kline JA, Courtney DM, et al. Evaluation of pulmonary embolism in the emergency department and consistency with a national quality measure: quantifying the opportunity for improvement. Arch Intern Med 2012;172: 1028-32.

15. Levine MB, Moore AB, Franck $C$, Li J, Kuehl DR. Variation in use of all types of computed tomography by emergency physicians. Am J Emerg Med 2013;31:1437-42.

16. Foy AJ, Liu G, Davidson WR Jr, Sciamanna C, Leslie DL. Comparative effectiveness of diagnostic testing strategies in emergency department patients with chest pain: an analysis of downstream testing, interventions, and outcomes. JAMA Intern Med 2015;175:428-36.

17. Goldstein NM, Kollef MH, Ward S, Gage BF. The impact of the introduction of a rapid D-dimer assay on the diagnostic evaluation of suspected pulmonary embolism. Arch Intern
Med 2001;161:567-71.

18. Yin $P$, Kiss $A$, Leis JA. Urinalysis orders among patients admitted to the general medicine service. JAMA Intern Med 2015; 175:1711-3.

19. Ong S, Nakase J, Moran GJ, et al. Antibiotic use for emergency department patients with upper respiratory infections: prescribing practices, patient expectations, and patient satisfaction. Ann Emerg Med 2007;50:213-20.

20. Schuur JD, Chambers JG, Hou PC. Urinary catheter use and appropriateness in U.S. emergency departments, 1995-2010. Acad Emerg Med 2014;21:292-300.

21. Wennberg J, Gittelsohn. Small area variations in health care delivery. Science 1973;182:1102-8.

22. Fisher ES, Wennberg DE, Stukel TA, Gottlieb DJ, Lucas FL, Pinder EL. The implications of regional variations in Medicare spending. Part 2: health outcomes and satisfaction with care. Ann Intern Med 2003;138:288-98.

23. Wennberg JE, Barnes BA, Zubkoff M. Professional uncertainty and the problem of supplier-induced demand. Soc Sci Med 1982;16:811-24.

24. Hakim I, Hathi S, Nair A, Narula T, Bhattacharya J. Electronic health records and the frequency of diagnostic test orders. Am J Manag Care 2017;23:e16-23.

25. Newton EH, Zazzera EA, Van Moorsel G, Sirovich BE. Undermeasuring overuse: an examination of national clinical performance measures. JAMA Intern Med 2015;175:1709-11.

26. Emanuel EJ, Fuchs VR. The perfect storm of overutilization. JAMA 2008;299:2789-91.

27. Waxman DA, Ridgely MS, Heaton $P$. The effect of malpractice reform on emergency department care. N Engl J Med 2015; 372:192.

28. Frei S. Regarding "emergency physician perceptions of medically unnecessary advanced diagnostic imaging". Acad Emerg Med 2015;22:1231.

29. Hess EP, Grudzen CR, Thomson R, Raja AS, Carpenter CR. Shared decision-making in the emergency department: respecting patient autonomy when seconds count. Acad Emerg Med 2015;22:856-64.

30. van der Weijden $T$, van Velsen $M$, Dinant GJ, van Hasselt CM, Grol R. Unexplained complaints in general practice: prevalence, patients' expectations, and professionals' test-ordering behavior. Med Decis Making 2003;23:226-31.

31. Mangione-Smith R, McGlynn EA, Elliott MN, Krogstad P, Brook $\mathrm{RH}$. The relationship between perceived parental expectations and pediatrician antimicrobial prescribing behavior. Pediatrics 1999;103:711-8.

32. Campbell EG, Regan $\mathrm{S}$, Gruen $\mathrm{RL}$, et al. Professionalism in 
medicine: results of a national survey of physicians. Ann Intern Med 2007;147:795-802.

33. Karras DJ, Ong S, Moran GJ, et al. Antibiotic use for emergency department patients with acute diarrhea: prescribing practices, patient expectations, and patient satisfaction. Ann Emerg Med 2003;42:835-42.

34. Devereaux PJ, Anderson DR, Gardner MJ, et al. Differences between perspectives of physicians and patients on anticoagulation in patients with atrial fibrillation: observational study. BMJ 2001;323:1218-22.

35. Lee CN, Hultman CS, Sepucha K. Do patients and providers agree about the most important facts and goals for breast reconstruction decisions? Ann Plast Surg 2010;64:563-6.

36. Zikmund-Fisher BJ, Sarr B, Fagerlin A, Ubel PA. A matter of perspective: choosing for others differs from choosing for yourself in making treatment decisions. J Gen Intern Med 2006;21:618-22.

37. Rao JK, Weinberger M, Kroenke K. Visit-specific expectations and patient-centered outcomes: a literature review. Arch Fam Med 2000;9:1148-55.

38. Coenen $\mathrm{S}$, Francis $N$, Kelly $M$, et al. Are patient views about antibiotics related to clinician perceptions, management and outcome? A multi-country study in outpatients with acute cough. PLoS One 2013;8:e76691.

39. Peck BM, Ubel PA, Roter DL, et al. Do unmet expectations for specific tests, referrals, and new medications reduce patients' satisfaction? J Gen Intern Med 2004;19:1080-7.

40. Hamm RM, Hicks RJ, Bemben DA. Antibiotics and respiratory infections: are patients more satisfied when expectations are met? J Fam Pract 1996;43:56-62.

41. Deyo RA, Diehl AK, Rosenthal M. Reducing roentgenography use: can patient expectations be altered? Arch Intern Med 1987;147:141-5.

42. Mainous AG 3rd, Zoorob RJ, Oler MJ, Haynes DM. Patient knowledge of upper respiratory infections: implications for antibiotic expectations and unnecessary utilization. J Fam Pract 1997;45:75-83.

43. Linder JA, Singer DE. Desire for antibiotics and antibiotic prescribing for adults with upper respiratory tract infections. J Gen Intern Med 2003;18:795-801.

44. Kendrick D, Fielding K, Bentley E, Kerslake R, Miller P, Pringle $M$. Radiography of the lumbar spine in primary care patients with low back pain: randomised controlled trial. BMJ 2001; 322:400-5.

45. Jarvik JG, Hollingworth $W$, Martin $B$, et al. Rapid magnetic resonance imaging vs radiographs for patients with low back pain: a randomized controlled trial. JAMA 2003;289:2810-8.
46. Taylor C, Benger JR. Patient satisfaction in emergency medicine. Emerg Med J 2004;21:528-32.

47. Butler CC, Rollnick S, Pill R, Maggs-Rapport F, Stott N. Understanding the culture of prescribing: qualitative study of general practitioners' and patients' perceptions of antibiotics for sore throats. BMJ 1998;317:637-42.

48. Toma G, Triner W, McNutt LA. Patient satisfaction as a function of emergency department previsit expectations. Ann Emerg Med 2009;54:360-7.

49. Melnick ER, Shafer K, Rodulfo N, et al. Understanding overuse of computed tomography for minor head injury in the emergency department: a triangulated qualitative study. Acad Emerg Med 2015;22:1474-83.

50. Hickson GB, Jenkins AD. Identifying and addressing communication failures as a means of reducing unnecessary malpractice claims. N C Med J 2007;68:362-4.

51. Kiesler DJ, Auerbach SM. Optimal matches of patient preferences for information, decision-making and interpersonal behavior: evidence, models and interventions. Patient Educ Couns 2006;61:319-41.

52. Hickson GB, Clayton EW, Githens PB, Sloan FA. Factors that prompted families to file medical malpractice claims following perinatal injuries. JAMA 1992;267:1359-63.

53. Hickson GB, Clayton EW, Entman SS, et al. Obstetricians' prior malpractice experience and patients' satisfaction with care. JAMA 1994;272:1583-7.

54. Stivers T, Mangione-Smith R, Elliott MN, McDonald L, Heritage J. Why do physicians think parents expect antibiotics? What parents report vs what physicians believe. J Fam Pract 2003;52:140-8.

55. van Driel ML, De Sutter $A$, Deveugele $M$, et al. Are sore throat patients who hope for antibiotics actually asking for pain relief? Ann Fam Med 2006;4:494-9.

56. Sanchez-Menegay C, Hudes ES, Cummings SR. Patient expectations and satisfaction with medical care for upper respiratory infections. J Gen Intern Med 1992;7:432-4.

57. Rhodes LA, McPhillips-Tangum CA, Markham C, Klenk R. The power of the visible: the meaning of diagnostic tests in chronic back pain. Soc Sci Med 1999;48:1189-203.

58. McPhillips-Tangum CA, Cherkin DC, Rhodes LA, Markham C. Reasons for repeated medical visits among patients with chronic back pain. J Gen Intern Med 1998;13:289-95.

59. Rolfe A, Burton C. Reassurance after diagnostic testing with a low pretest probability of serious disease: systematic review and meta-analysis. JAMA Intern Med 2013;173:40716.

60. Rothberg MB, Sivalingam SK, Ashraf J, et al. Patients' and 
cardiologists' perceptions of the benefits of percutaneous coronary intervention for stable coronary disease. Ann Intern Med 2010;153:307-13.

61. Vanden Eng J, Marcus R, Hadler JL, et al. Consumer attitudes and use of antibiotics. Emerg Infect Dis 2003;9:1128-35.

62. Carman KL, Maurer M, Yegian JM, et al. Evidence that consumers are skeptical about evidence-based health care. Health Aff (Millwood) 2010;29:1400-6.

63. Doust J, Del Mar C. Why do doctors use treatments that do not work? BMJ 2004;328:474-5.

64. Hoffmann TC, Del Mar C. Patients' expectations of the benefits and harms of treatments, screening, and tests: a systematic review. JAMA Intern Med 2015;175:274-86.

65. Hoffmann TC, Del Mar C. Clinicians' expectations of the benefits and harms of treatments, screening, and tests: a systematic review. JAMA Intern Med 2017;177:407-19.

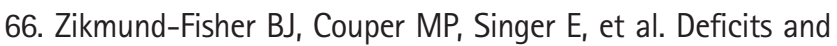
variations in patients' experience with making 9 common medical decisions: the DECISIONS survey. Med Decis Making 2010;30:85S-95S.

67. Rothberg MB, Sivalingam SK, Kleppel R, Schweiger M, Hu B, Sepucha KR. Informed decision making for percutaneous coronary intervention for stable coronary disease. JAMA Intern Med 2015;175:1199-206.

68. Fried TR, Tinetti ME, Towle V, O'Leary JR, lannone L. Effects of benefits and harms on older persons' willingness to take medication for primary cardiovascular prevention. Arch Intern Med 2011;171:923-8.

69. Institute of Medicine. Crossing the quality chasm: a new health system for the 21st century. Washington, DC: National Academy Press; 2001.

70. American College of Emergency Physicians. Code of ethics for emergency physicians [Internet]. Dallas, TX: American College of Emergency Physicians; 2017 [cited 2017 Apr 21]. Available from: https://www.acep.org/Clinical---PracticeManagement/Code-of-Ethics-for-Emergency-Physicians/.

71. Kunneman M, Montori VM, Castaneda-Guarderas A, Hess EP. What is shared decision making? (and what it is not). Acad Emerg Med 2016;23:1320-4.

72. Kon AA. The shared decision-making continuum. JAMA 2010; 304:903-4.

73. Davis MA, Hoffman JR, Hsu J. Impact of patient acuity on preference for information and autonomy in decision making. Acad Emerg Med 1999;6:781-5.

74. Charles C, Gafni A, Whelan T. Decision-making in the physician-patient encounter: revisiting the shared treatment decision-making model. Soc Sci Med 1999;49:651-61.
75. Stacey $D$, Legare $F$, Lewis $K$, et al. Decision aids for people facing health treatment or screening decisions. Cochrane Database Syst Rev 2017;4:CD001431.

76. Isaacs CG, Kistler $C$, Hunold KM, et al. Shared decision-making in the selection of outpatient analgesics for older individuals in the emergency department. J Am Geriatr Soc 2013; 61:793-8.

77. Deyo RA, Cherkin DC, Weinstein J, Howe J, Ciol M, Mulley AG Jr. Involving patients in clinical decisions: impact of an interactive video program on use of back surgery. Med Care 2000; 38:959-69.

78. Geyer BC, Xu M, Kabrhel C. Patient preferences for testing for pulmonary embolism in the ED using a shared decision-making model. Am J Emerg Med 2014;32:233-6.

79. Hess EP, Hollander JE, Schaffer JT, et al. Shared decision making in patients with low risk chest pain: prospective randomized pragmatic trial. BMJ 2016;355:i6165.

80. Kline JA, Zeitouni RA, Hernandez-Nino J, Jones AE. Randomized trial of computerized quantitative pretest probability in low-risk chest pain patients: effect on safety and resource use. Ann Emerg Med 2009;53:727-35.

81. Elwyn G, Tilburt J, Montori V. The ethical imperative for shared decision-making. Eur J Pers Cent Healthc 2013;1:129-31.

82. Katz SJ, Hawley $\mathrm{S}$. The value of sharing treatment decision making with patients: expecting too much? JAMA 2013;310: 1559-60.

83. Levinson W, Kao A, Kuby A, Thisted RA. Not all patients want to participate in decision making: a national study of public preferences. J Gen Intern Med 2005;20:531-5.

84. Coulter A, Jenkinson C. European patients' views on the responsiveness of health systems and healthcare providers. Eur J Public Health 2005;15:355-60.

85. Coulter A. Paternalism or partnership? Patients have grown up-and there's no going back. BMJ 1999;319:719-20.

86. Yamamoto $L G$, Young $L L$, Roberts JL. Informed consent and parental choice of anesthesia and sedation for the repair of small lacerations in children. Am J Emerg Med 1997;15:285-9.

87. Chewning B, Bylund CL, Shah B, Arora NK, Gueguen JA, Makoul G. Patient preferences for shared decisions: a systematic review. Patient Educ Couns 2012;86:9-18.

88. Frosch DL, May SG, Rendle KA, Tietbohl C, Elwyn G. Authoritarian physicians and patients' fear of being labeled 'difficult' among key obstacles to shared decision making. Health Aff (Millwood) 2012;31:1030-8.

89. Charles C, Gafni A, Whelan T. Shared decision-making in the medical encounter: what does it mean? (or it takes at least two to tango). Soc Sci Med 1997:44:681-92. 
90. Street RL Jr, Gordon HS, Ward MM, Krupat E, Kravitz RL. Patient participation in medical consultations: why some patients are more involved than others. Med Care 2005;43:960-9.

91. Probst MA, Kanzaria HK, Frosch DL, et al. Perceived appropriateness of shared decision-making in the emergency department: a survey study. Acad Emerg Med 2016;23:375-81.

92. Kanzaria HK, Brook RH, Probst MA, Harris D, Berry SH, Hoffman JR. Emergency physician perceptions of shared decisionmaking. Acad Emerg Med 2015;22:399-405.

93. McCaffery KJ, Holmes-Rovner M, Smith SK, et al. Addressing health literacy in patient decision aids. BMC Med Inform Decis Mak 2013;13 Suppl 2:S10.

94. Durand MA, Carpenter $L$, Dolan $H$, et al. Do interventions designed to support shared decision-making reduce health inequalities? A systematic review and meta-analysis. PLoS One 2014;9:e94670.

95. Hoffmann TC, Legare F, Simmons MB, et al. Shared decision making: what do clinicians need to know and why should they bother? Med J Aust 2014;201:35-9.

96. Chen EH, Kanzaria HK, Itakura K, Booker-Vaughns J, Yadav K, Kane BG. The role of education in the implementation of shared decision making in emergency medicine: a research agenda. Acad Emerg Med 2016;23:1362-7.

97. Couet N, Desroches $S$, Robitaille $H$, et al. Assessments of the extent to which health-care providers involve patients in decision making: a systematic review of studies using the OPTION instrument. Health Expect 2015;18:542-61.

98. Lin GA, Redberg RF. Addressing overuse of medical services one decision at a time. JAMA Intern Med 2015;175:1092-3.

99. Stickrath C, Druck J, Hensley N, Maddox TM, Richlie D. Patient and health care provider discussions about the risks of medical imaging: not ready for prime time. Arch Intern Med 2012;172:1037-8.

100. Lin GA, Dudley RA, Redberg RF. Cardiologists' use of percutaneous coronary interventions for stable coronary artery disease. Arch Intern Med 2007;167:1604-9.

101. Jha S. Uncertainty and the diagnostic leviathan. JAMA Intern Med 2015;175:1085-6.
102. Prasad V, Vandross $A$, Toomey $C$, et al. A decade of reversal: an analysis of 146 contradicted medical practices. Mayo Clin Proc 2013;88:790-8.

103. Easterbrook PJ, Berlin JA, Gopalan R, Matthews DR. Publication bias in clinical research. Lancet 1991;337:867-72.

104. Zorzela L, Golder S, Liu Y, et al. Quality of reporting in systematic reviews of adverse events: systematic review. BMJ 2014;348:f7668

105. Carpenter CR, Raja AS. Arming the Bayesian physician to rule out pulmonary embolism: using evidence-based diagnostics to combat overtesting. Acad Emerg Med 2014;21:1036-8.

106. Lenzer J. Why we can't trust clinical guidelines. BMJ 2013; 346:f3830.

107. Montori VM, Brito JP, Murad MH. The optimal practice of evidence-based medicine: incorporating patient preferences in practice guidelines. JAMA 2013;310:2503-4.

108. Djulbegovic B, Guyatt $\mathrm{GH}$. Evidence-based practice is not synonymous with delivery of uniform health care. JAMA 2014; 312:1293-4.

109. Caverly TJ, Prochazka AV, Stickrath C. Do physicians have an obligation to disclose the uncertainty about harms or just the harms? Reply. JAMA Intern Med 2013;173:1752.

110. Fenton JJ, Kravitz RL, Jerant $A$, et al. Promoting patient-centered counseling to reduce use of low-value diagnostic tests: a randomized clinical trial. JAMA Intern Med 2016;176:191-7.

111. Mangione-Smith R, McGlynn EA, Elliott MN, McDonald L, Franz CE, Kravitz RL. Parent expectations for antibiotics, physician-parent communication, and satisfaction. Arch Pediatr Adolesc Med 2001;155:800-6.

112. Brett AS, McCullough LB. Addressing requests by patients for nonbeneficial interventions. JAMA 2012;307:149-50.

113. Deyo RA. Imaging idolatry: the uneasy intersection of patient satisfaction, quality of care, and overuse. Arch Intern Med 2009;169:921-3.

114. Durand MA, Moulton B, Cockle E, Mann M, Elwyn G. Can shared decision-making reduce medical malpractice litigation? A systematic review. BMC Health Serv Res 2015;15:167. 